\title{
WATCHMEN Y LOS PARADIGMAS NOVELÍSTICOS DEL ESCRITOR ESPAÑOL
}

\author{
Watchmen and the spanish writer novelistics paradigms
}

\section{Pablo Sánchez*}

\begin{abstract}
RESUMEN
En este artículo se propone un análisis de algunas de las características literarias fundamentales de Watchmen, la novela gráfica de Alan Moore, y se plantea la función que esas características podrían cumplir como modelo para los novelistas contemporáneos, particularmente en la literatura española, que hasta la fecha no ha asimilado esa influencia. El punto de partida del estudio es que Watchmen contiene una serie de valores narrativos que son comparables con algunos de los modelos de la novela de la modernidad y que por tanto puede ocupar una posición similar en el conjunto de las posibilidades literarias de hoy.

Palabras clave: Watchmen, Alan Moore, Novela gráfica, Literatura española, Modernidad literaria.
\end{abstract}

\begin{abstract}
This article proposes an analysis of some fundamental literary characteristics of Watchmen, the graphic novel by Alan Moore, and considers the possible role of these characteristics as a model for the contemporary novelists, particularly in Spanish literature, which to date has not absorbed the influence. The starting point of the study is that Watchmen contains a series of narrative values which are comparable to some of the models of the modern novel and therefore can occupy a similar position in the whole of the literary possibilities of today. Keywords: Alan Moore, Watchmen, Graphic novel, Spanish Literature, Modernism.
\end{abstract}

* Universidad de Sevilla. Profesor y novelista de Literatura Española e Hispanoamericana. España Correo electrónico: psanchez3@us.es Recepción:27/4/16. Aceptación:3/4/16. 
La complejidad y heterogeneidad de los fenómenos de la cultura contemporánea está generando, al amparo de métodos críticos como los de los estudios culturales, una diversidad casi incontrolable de enfoques y análisis que escapan a las categorías canónicas de lo que podríamos llamar el humanismo tradicional. Esas transformaciones operadas tanto en el terreno estético como en el crítico están haciendo también vulnerables y discutibles muchos conceptos, y a la vez ampliando el repertorio de posibilidades para creadores e investigadores. Uno de ellos, por supuesto, es el de "novela", concepto central de la cultura moderna, sometido a múltiples tensiones (tecnológicas, mercantiles, ideológicas, etc.) en la actualidad, y también dilatado gracias a hibridaciones y fecundaciones creativas de muy diverso signo. En ese sentido, uno de los resultados más interesantes, complejos y difíciles de abordar sería el de "novela gráfica", término cada vez más popular pero bastante impreciso con el que se pretende distinguir algunos cómics especialmente unitarios, densos y complejos estructuralmente, frente a los antiguos cómics seriales. El famoso premio Eisner, inaugurado en 1988, podría servir como inicio de la legitimación institucional de esa práctica artística.

Como sabemos, en la historia de la novela gráfica destaca, por su posición central y totémica, la figura de Alan Moore. En estas páginas intentaremos plantear una nueva reflexión sobre la novela gráfica fundacional, Watchmen, pero incidiendo claramente en la primera parte del sintagma, es decir, en el porcentaje novelesco de la obra, en su gozosa y exultante narratividad, que intentaremos contrastar con algunos paradigmas novelísticos del siglo $\mathrm{XX}$ para tratar de calibrar el sentido y la importancia de Watchmen más allá de los códigos del cómic y en el conjunto de lo que podríamos llamar genéricamente el sistema cultural occidental o eso que, antes de la posmodernidad, se conoció y santificó como "alta cultura". El propio Moore se ha referido alguna vez a esa obra suya como una novela (Marín 2009: 71), lo que facilita el ejercicio comparativo y nos permitirá discutir si Watchmen puede "competir" estéticamente con los modelos novelescos más conocidos y consagrados, sobre todo para los novelistas españoles de la actualidad.

Situemos brevemente la novedad revolucionaria de Moore en la diacronía del género. Antes de Watchmen, el cómic de superhéroes, sobre todo en la factoría Marvel, había evolucionado desde los esquemas iniciales de Stan Lee, Roy Thomas y otros en dos direcciones especialmente interesantes. Una primera dirección más realista fue la liderada por el británico Chris Claremont, que descubrió el potencial del tema mutante para incluir una dimensión crítica, que conectaba el mundo de los superhéroes con las urgencias históricas y los dilemas éticos, y que renovaba al mismo tiempo el código incluyendo dosis de reflexividad y verosimilitud.

La segunda dirección que fue la del desbordamiento imaginativo por vía cosmogónica, ya iniciado por Stan Lee cuando, célebremente, decidió enfrentar a los Cuatro Fantásticos contra un ser divino como Galactus; pero esa dirección fue ampliada hasta límites metafísicamente deslumbrantes en su espontaneidad gracias a autores como Jim Starlin (The Death of Captain Marvel) o Jim Shooter (Secret Wars), especialmente en la colección The Avengers. Marvel descubrió así el terreno sin límites de la hipótesis cosmológica, que exploró con audacia y resultados más diversos e impredecibles que, por poner un ejemplo, la mitología superficialmente multicultural y simplona (a pesar de la influencia de Joseph Campbell) de Star Wars. Si pensamos que en el arte secularizado y culto de la segunda mitad del siglo XX la conjetura metafísica quedó en retroceso (salvo excepciones como Borges), lo que esas historietas recuperaban era la inocencia creativa de volver a pensar en Dios como personaje y crear una especie de politeísmo maravilloso en el que todo es posible menos -curiosamente- la omnipotencia, porque siempre puede haber algún dios más poderoso en un universo o multiverso que escapa a nuestra comprensión racional. 
En ese sentido, a pesar de sus limitaciones retóricas y sus implicaciones ideológicas, el cómic Marvel logró unos interesantes resultados artísticos, muy superiores al viejo estilo de Stan Lee (y a la oferta de DC). Unos resultados que, curiosamente, venían a compensar algunas carencias que los paradigmas narrativos cultos habían empezado a manifestar, obsesionados por la autorreferencialidad y los peores defectos de la posmodernidad. El cómic se convirtió, de forma inesperada, en un refugio para preocupaciones y temas que la novela había superado en su camino de secularización y racionalización y que algunos lectores ansiosos de curiosidad metafísica encontraron felizmente representados. La gnosis marveliana y la galaxia mutante, con sus personajes humanos, demasiado humanos, fertilizaban la imaginación que para algunos lectores estaba desapareciendo visiblemente de muchas opciones novelísticas a nuestro alcance (por ejemplo, muy claramente en la narrativa española del siglo XX, ejemplo histórico de escasez de imaginación y fantasía).

De todas maneras, aun suponiendo que el cómic Marvel tenía un yacimiento de posibilidades creativas a su alcance, y que las desarrollaba con el talento de guionistas importados a menudo de Europa, seguía estigmatizado por algunas rigideces del código del género: por ejemplo, los diálogos a menudo irrealistas, patriarcales y pueriles, la simplicidad psicológica y especialmente afectiva, las concesiones de inverosimilitud por exigencias mercantiles (por ejemplo, la alergia a matar definitivamente a los personajes, o simplemente a concederles temporalidad, a situarlos en el tiempo y en su forzoso desgaste) o el inevitable toque neocolonial estadounidense, con la defensa de determinados valores ideológicos nada exigentes desde el punto de vista intelectual. Por todo ello, cualquier lector académicamente formado podía disfrutar del cómic con la conciencia de que era un producto valioso y digno, pero obviamente mejorable. Porque la epistemología posmoderna con su revalorización de lo marginal y anticanónico ha descentralizado la idea de alta cultura, pero no está claro que todos los productos culturales sean intrínseca y constitutivamente igual de complejos, y por tanto podría sostenerse hay una diferencia objetiva, no sagrada pero sí objetiva e inmanente, entre, pongamos por caso de manera completamente arbitraria y provocadora, Tintín y La Montaña mágica. O entre Los inmortales de Russell Mulcahy y El inmortal de Jorge Luis Borges.

En ese contexto es en el que se publican las dos obras que modificaron definitivamente la evolución del género: Batman: The Dark Knight Returns (1986), de Frank Miller y, muy especialmente, Watchmen (1986-87). El impacto de Miller fue sin duda importante, pero lo que Watchmen presentaba era algo mucho más importante: un efecto estético comparable al de las grandes novelas de la modernidad, es decir, un producto difícil (pero no hermético) que ofrecía una imagen compleja del mundo recurriendo a diversas técnicas y planteamientos estéticos.

Lo más fácil era, desde luego, diagnosticarlo como un cómic adulto, pero ese adjetivo es evidentemente inapropiado, ya que somete al cómic al injusto estigma del infantilismo, sobradamente superado ya hoy. No es descabellado pensar que el impacto de Watchmen se pareció más, por ejemplo, a la experiencia deslumbrante que sintieron, de manera inesperada, los lectores latinoamericanos con las novelas del boom: el orgullo único e irrepetible de encontrar la respuesta a unas preguntas estéticas, a unas necesidades insatisfechas, en otras palabras, la esperada dignificación de un género, de una práctica que por fin se volvía inequívocamente artística.

Por ello, se podría comparar Watchmen con algunos jalones de la historia de la novela: ya se ha dicho más de una vez que el cómic de Moore tiene algo de cervantino y también incluso de joyceano. Esas comparaciones, posiblemente, son eufóricas y requieren algo de prudencia y respeto a las medidas y a las escalas; quizá sería más apropiado y realista situar Watchmen en comparación con las revisiones del western que van desde The Man Who Shot Liberty Valance hasta Unforgiven; no obstante, ninguno de esos ejercicios de recodificación 
de un género cinematográfico alcanza el nivel de sofisticación retórica y semántica de la obra de Moore, auténtico compendio de temas, recursos y modelos narrativos y visuales. Por eso quizá sea preferible, a pesar de todo, comparar Watchmen con la novela occidental como objeto artístico especialmente complejo $y$ denso en significados, y en particular con el concepto moderno de la novela como forma de conocimiento a la manera de escritores como Milan Kundera (El arte de la novela) o Ernesto Sábato (El escritor y sus fantasmas); la novela como ejercicio interpretativo, como rescate de la unidad del ser frente a los métodos cartesianos y la especialización científica y filosófica.

Podríamos recordar algunos aspectos que hacen de Watchmen un producto abarcador, sintetizador, totalizador incluso, como aquellas novelas totales de las que se habló en otra época y que ahora han quedado marginadas por las exigencias del mercado y la rebaja de los niveles de exigencia a que nos ha llevado el neoliberalismo cultural. Watchmen no sólo recoge una tradición, que es la del cómic de superhéroes; trabaja con otros muchos modelos y códigos, empezando por el policiaco, cuyo ritual (el descubrimiento del cadáver) centra el primer capítulo. También, anticipa el cine de violencia y psicópatas de los noventa con Rorschach; incluye historias de amor con su toque melodramático gracias a Búho Nocturno y Miss Júpiter y el relato de aventuras con el relato en segundo grado de Max Shea; aborda la preocupación cosmogónico-metafísica con la deificación del Dr. Manhattan y hasta incluye, en su imagen total, la cuestión ideológica, puesto que al fin y al cabo Watchmen es una obra sobre la Guerra Fría y el conflicto esencial entre capitalismo y comunismo que duró más de cuarenta años. Por supuesto, no hay arengas políticas ni ideologemas panfletarios, pero eso no invalida la audacia de Moore, porque se enfrenta a un tema máximo, límite, como fue el Apocalipsis nuclear.

Hoy puede parecer caduco el tema, puesto que apenas tres años después de la publicación de Watchmen cayó de forma pacífica el bloque comunista y entramos en el Fin de la Historia según Francis Fukuyama, con lo que el plan megalómano de Ozymandias se revelaba como exagerado e innecesario, ya que el mundo solucionó la tensión nuclear de una forma extrañamente fácil y quizá impredecible unos pocos años antes. En ese sentido, Watchmen podría parecer obsoleto, o traicionado por una evolución histórica que trivializó la magnitud de su sentido inquietante y amenazador; pero también podríamos decir que es exactamente al revés, que hay que volver a Watchmen para entender la obra precisamente por su hondo sentido histórico, que nos permite recuperar una época que creemos superada y que sin embargo hemos superado sólo de forma superficial. Porque las nuevas tecnologías de la comunicación, el mundo global y su doctrina de la ansiedad y el shock a través de los medios de comunicación de masas nos hacen ver apocalipsis cada año y trascendentales cambios históricos cada seis meses: la primera guerra de Irak, los atentados del 11 de setiembre, la segunda guerra de Irak, la crisis económica de hoy y tantos otros acontecimientos son sin duda temibles y decisivos pero pasan al olvido rápidamente como parte de esa estrategia del miedo y la alienación que caracteriza la sociedad actual de la información. Sin embargo, hay que recordar que todas las crisis son terribles, pero el Apocalipsis es otra cosa. Hablamos del Apocalipsis nuclear, que junto con el Holocausto judío son las dos grandes demostraciones de cómo Occidente consiguió en el siglo XX perfeccionar su capacidad para el exterminio. Hablamos de que a mediados de los ochenta el ser humano tenía capacidad absoluta para la destrucción de la vida completa del planeta Tierra y estaba en disposición de usarla. Chernóbil, en ese sentido, fue sólo una prueba a pequeñísima escala del poder terrible del átomo.

¿Cómo no sentir fascinación artística ante el Apocalipsis como tema máximo, total, absoluto? Moore no quiso entrar en el debate ideológico, sino que se esforzó en sortearlo con visos anarcoides o abstencionistas; pero de todos modos se enfrentó al absoluto, porque ese fue durante años el tema más serio de la humanidad y casi nadie, en el mundo del arte, 
parecía darse cuenta. Y, como veremos, lo hizo en una operación creativa de inconcebible sutileza y magnanimidad con esos personajes a los que primero destroza sistemáticamente arrebatándoles todo su status heroico pero a los que al final, en un acto que quizá le debía haber dado Cervantes a don Quijote pero no le dio, les devuelve por la vía sorpresiva su condición heroica al dejarlos ante la decisión inigualable de salvar o no al mundo en el último capítulo de la serie.

Los novelistas, contagiados más de la cuenta por la posmodernidad y sus nuevas prioridades, hace tiempo que parecen no querer hablar de absolutos amparándose en desconfianzas filosóficas hacia grandes relatos y grandes conceptos; con ello a menudo se reducen a localismos, referencias librescas idóneas para el onanismo escritural, parques temáticos de historia, pequeños problemas y anécdotas propicias para entretener la mentalidad del ciudadano consumidor que es el sujeto medio de la democracia liberal. Moore, y eso es algo que hay que agradecerle infinitamente, quitó el freno de la imaginación narrativa y decidió subir la apuesta sin miedo a las comparaciones o al fracaso, consciente de que el suyo era un terreno virginal y que podía modernizar el género sin temor a que le tomaran por un vulgar imitador de Dostoievski o Thomas Mann. En ese sentido, su artificiosidad totalizadora puede parecer pedante o pretenciosa a los lectores cultos acostumbrados a la gran novela moderna culminada en Ulises y puede ser leída como un gesto anacrónico y oportunista de aplicación de modelos ya descartados por la novela; pero, en nuestra opinión, esa interpretación tiene un doble error complementario: es demasiado exigente con Moore y demasiado indulgente con la novela y la producción supuestamente culta actual.

En muchos sentidos, además, Watchmen es un ejemplo perfecto para los postulados de la teoría literaria del siglo XX. No sólo, naturalmente, ejemplifica la modificación del horizonte de expectativas en los términos de Hans Robert Jauss, es decir, es un caso perfecto de distancia estética entre dos horizontes, el previo y el posterior a la aparición de la obra. También, podría aplicársele, con sólo un poco de manga ancha, el concepto de extrañamiento o desfamiliarización (ostranenie) de los formalistas rusos. Efectivamente, Watchmen se ordena sobre una desautomatización enfática: la de la figura del superhéroe. Moore altera en profundidad nuestra percepción automatizada del superhéroe tal y como lo habían definido y esquematizado Marvel y DC desde los años cuarenta del siglo XX: diseña superhéroes con características familiares a los aficionados del cómic y los enfrenta a diferentes condiciones (salvo una, todas básicamente realistas) para enseñarnos lo absurdo, alienante y ridículo (amén de antidemocrático) que es el propio concepto de superhéroe. Nos revela su arbitrariedad, su condición artificial y antirrealista.

Recapitulemos rápidamente toda las reinvenciones del superhéroe, mucho más audaces, agresivas y desmitificadoras que los esfuerzos previos realizados con personajes ya no tan planos como Batman o Lobezno o Magneto. En Watchmen, en primer lugar, sólo uno de los superhéroes tiene superpoderes (aunque podríamos discutir si Ozymandias es fantástico o realista en algunas de sus habilidades excepcionales): nos referimos al Dr. Manhattan, cuyo apodo ya muestra una evidentísima ridiculización del héroe convertido en instrumento de propaganda. Pero es que además no es sólo un superhéroe, sino que es un superhéroe casi omnipotente y omnisciente (el casi es decisivo en la historia, como sabemos), que por tanto representa la deshumanización absoluta del héroe. En ese sentido, hay que recalcar cómo Moore es capaz de tomar a un semidiós o demiurgo y adjudicarle con total naturalidad narrativa el nombre ridículo de Dr. Manhattan, en un procedimiento oximorónico que no está tan lejos de ese Borges que incluye el objeto total, el Aleph, en el sótano de la casa de un poeta mediocre argentino.

Pero la gama de antihéroes es mucho más rica: en sagaz simetría con el héroe deshumanizado tenemos los héroes patológicos: el narcisista Adrian Veidt, el psicópata y sociópata Rorschach y el violador fascista Comediante. En 
medio, en la perfecta neutralidad de su apatía y su mediocridad, tenemos al Búho Nocturno, y con él a Miss Jupiter con su caótica vida sentimental y familiar. Pero los resortes de la desmitificación no acaban ahí, y bastaría recordar la importancia de la violación de Silk Spectre para entender que Moore no sólo desmitifica al héroe sino su inherente masculinidad agresiva y violenta.

La oferta de héroes presenta, por tanto, relieves desconocidos para el género y lógicamente recodifica con sentido crítico y transgresor toda su simbología y sus valores. En ese sentido, en su riqueza y diversidad, Moore juega de forma asombrosa con una de las funciones básicas de la narratividad: el héroe. Aquí vendría bien recordar los planteamientos lukacsianos sobre el héroe y su enfrentamiento con el mundo que caracterizan las diversas etapas del paso de la épica a la novela (Lukács, 1971); en el caso de Moore, no son únicamente funciones de héroe, sino que tienen retórica de héroe y se nombran a sí mismos como tales. A primera vista, precisamente por ser héroes y asumirse de forma explícita como tales, están, en apariencia, lejos de los protagonistas complejos de las principales novelas modernas, imposibles de reducir a una única definición o categoría y a menudo misteriosos u opacos, como en Kafka o Camus, o reflexivos e intelectuales, como en Musil o Mann.

Sin embargo, podríamos afirmar aquí que Moore, que en tantos otros aspectos es complejo y sofisticado, brilla precisamente porque es anacrónico y trabaja con materiales (los personajes) delimitados por la cuadrícula del héroe, lo cual es de algún modo, un retorno al origen de la narratividad épica, Aquiles. Pero lo que hace Moore es clausurarla de un modo creativo, en una regeneración sorprendente que aúna parodia y homenaje, destrucción y creación, devaluación y consagración. Nos referimos concretamente a la increíble generosidad de Moore como creador y a la operación final de Watchmen: después de haber desmontado de manera metódica todas las funciones del héroe, después de haber sometido a sus personajes a una despiadada crítica y a una desvalorización completa, les devuelve su naturaleza original, los revitaliza y devuelve a la vida, logrando a través del increíble plan de Ozymandias ponerles ante un heroísmo absoluto, inesperado para ellos mismos y por supuesto para el lector. Los héroes patéticos y destruidos se encuentran al final ante su oportunidad suprema, ante la legitimidad que nunca habían tenido realmente y que ahora, por fin se les presenta en forma de decisivo debate moral. Como sabemos, los héroes toman diversas opciones ante ese dilema, en una última vuelta de tuerca con la que Moore llena más de sentido a su obra. Pero, al fin y al cabo, hay algo de pureza, de adanismo narrativo, de elementalidad, al volver a la figura esencial del héroe; y esa pureza es precisamente lo que compensa y equilibra, en nuestra opinión, la estructura compleja de la obra, las capas de artificio constructivo que podrían haber deparado un resultado final confuso, deletéreo o heteróclito.

El personaje vuelve a estar en el centro de la obra, y a diferencia de tantos experimentos narrativos contemporáneos, tiene contornos claros y precisos, sin necesidad de ser plano o superficial. Y la acción, la sucesión de hechos, se vuelve una lección para tanto narrador moroso o inane de nuestro mundo actual: Moore demuestra que se puede conciliar el artificio textual con la elementalidad de la ficción en sus atributos básicos.

Porque, en efecto, hay un complejo sistema textual en Watchmen, que salta a la vista inmediatamente y que demuestra por qué por otro lado decente versión cinematográfica de Zach Snyder no podía reunir en la pantalla todos los méritos en papel de la obra; los visuales sí, o al menos muchos de ellos, pero los literarios, no. En From Hell, el complemento textual y documental es importante, pero lo que sucede en Watchmen es más significativo y para entenderlo de nuevo nos puede ayudar la teoría literaria del siglo XX, con uno de sus conspicuos representantes, Mijail Bajtin. Recordemos que Mijail Bajtin planteaba el nacimiento de la novela con el fin de la concepción tolomeica del mundo y la entrada del plurilingüismo en la literatura (Bajtin 1989: 80-92). Para él, la novela es, básicamente, la diversidad social, organizada 
de manera artística, del lenguaje; recoge las múltiples estratificaciones internas del lenguaje, sean por profesiones, generaciones, corrientes, ideologías, o momentos históricos, todos ellos elementos orquestados por el autor para ofrecer relaciones y correlaciones que quedan armonizados artísticamente. En ese sentido, los textos complementarios de cada capítulo de Watchmen quizá no tienen mucho valor estético "literario", en términos de originalidad inmanente, pero cumplen la función de lo que Bajtin llama "los géneros intercalados", que son unidades compositivas que permiten la entrada de los discursos sociales.

Por ese motivo Watchmen tiene un valor estéticamente multidimensional. Los textos complementarios, o peritextos, siguen modelos que reflejan la diversidad social: informes médicos, cartas personales, artículos de prensa y tantos otros tipos de discurso diferenciado que relacionan el cómic con la complejidad social, lo insertan y relacionan con el conjunto de los discursos de una sociedad, lo vinculan al flujo ideológico, lo que es fundamental en la estrategia desautomatizadora de la que habíamos hablado antes. La desfamiliarización del héroe se consigue precisamente gracias a esa naturalidad, al socializarlo a través de discursos que complementan la psicología y la biografía de los personajes, amén de dar informaciones que amplían o detallan la historia narrada.

Con todos estos elementos de naturaleza estética, no debe extrañar la fascinación por Watchmen entre lectores habituales de novelas canónicas, y el puesto destacado que muchos le han asignado no sólo en su educación sentimental sino también en la formación de las expectativas estéticas. La pregunta que podríamos formularnos ahora, y que no tiene respuesta fácil, es qué posibilidades hay de que Watchmen realmente constituya o haya constituido una fuente de inspiración para el bando novelístico actual, en particular el de lengua española, que es el que más nos interesa; es decir, se trataría de pensar hasta qué punto Watchmen puede funcionar como uno más de los modelos estéticos de un novelista del siglo XXI.
Como es obvio, no estamos afirmando que sea necesario que un novelista español o latinoamericano de hoy escriba historias de superhéroes, sino que nos referimos a la posibilidad de que la novela gráfica fertilice la novela literaria y se establezcan interrelaciones entre prácticas artísticas (aunque no a un nivel comparable al de, por ejemplo, Neil Gaiman). No hablamos de cualquier novela gráfica, en realidad, sino de Watchmen, una muy concreta, canónica, ejemplar, que aunque fue publicada hace ya bastante tiempo sigue conservando, en nuestra opinión, un potente status creativo, una fuerza seminal que la hace vigente y activa como modelo expresivo.

Ciertamente, desde el momento ya lejano en que Cortázar creara el experimento Fantomas contra los vampiros multinacionales (1975), la literatura de lengua española ha ido asimilando y aprovechando el cómic como otros elementos más o menos considerados populares y propios de la nueva cultura del capitalismo tardío. En el caso concreto de España, tenemos casos curiosos como el de Víctor Mora, novelista y autor de cómics; aunque quizá más relevante es la atención que escritores como Terenci Moix, Luis Alberto de Cuenca e Ignacio Vidal-Folch han prestado en diferentes momentos al mundo del cómic.

El aval de Umberto Eco seguramente fue decisivo en ese progresivo respeto ganado por el arte de la historieta; hoy ya ni siquiera es una novedad absoluta, realmente, en términos de opción literaria, puesto que forma parte de una nueva versión de lo que Octavio Paz llamó la "tradición de la ruptura" y que tiene que ver no sólo con nichos de mercado literario, sino con la saturación de una tradición literaria inmanejable y con la inmadura tentación de la iconoclastia. Así, algunos novelistas se apoyan hoy muy explícitamente en la heterogeneidad actual de la producción cultural, aunque con una evidente y quizá discutible preferencia electrónica y sobre todo anglófila: pensemos en la llamada literatura afterpop, nocilla o "de implosión mediática", que ha adquirido cierta notoriedad en los últimos años como paradigma de una renovación formal con pretensiones programáticas y nuevos utillajes 
literarios aparentemente antihegemónicos y descentralizadores. Ejemplo de ello sería la importancia de los elementos visuales en la obra de Agustín Fernández Mallo, o en el experimento de Vicente Luis Mora, Alba Cromm.

Sin embargo, no queda claro que estos proyectos representen un modelo eficiente, en nuestra opinión, de absorción de nuevas formas expresivas como la que representó en su momento Watchmen y la que representan hoy algunas series de ficción televisiva, como The Wire o The Sopranos. Enumeraremos aquí algunas estrategias que, según los críticos Jordi Gracia y Domingo Ródenas, caracterizan a ese grupo de narradores españoles: "atomización extrema de las tramas, artificiosidad deliberada de las estructuras, intermitencia narrativa sin cohesión ni linealidad expositiva, recursos gráficos y tipográficos que deshacen la ilusión literaria, ilustraciones comentadas y exhibicionismo compulsivo de la voluntad de ruptura" (Gracia y Ródenas 2011: 969). Sin duda, el elemento visual puede conectarse sin dificultad con el cómic, pero no así la atomización de la trama o la falta de linealidad expositiva. En esos ámbitos es donde, precisamente Watchmen (y también, por ejemplo, The Wire) brilla en especial como musculatura narrativa, como tótem de un concepto de la ficción que articula, como hemos visto, complejidad y elementalidad en una nueva armonía, permitiendo que el texto trabaje racionalmente a partir de bases sólidas y reconocibles para llegar de forma coherente a una conclusión; una conclusión que no es sólo una tesis o un mensaje en sentido convencional o decimonónico, sino que es básicamente una imagen del mundo. Por ello, se puede concluir sin lugar a dudas que la huella de Watchmen aún no ha generado repercusiones literarias significativas al menos en español, y que su potencial sigue esperando creadores que asuman la fuerza modélica de la obra.

Quizá deberíamos equilibrar este análisis añadiendo, para terminar, las imperfecciones y las debilidades de Watchmen, que sin duda podrían ser añadidas y discutidas aquí; pero nuestra intención es justamente ensalzar Watchmen como modelo, como ejemplo de creatividad y reto artístico en el mundo actual no sólo para el cómic, que hace tiempo que aprendió la lección, sino también para el género novelístico, al que, quizá, le hacen falta más inyecciones de vitalidad narrativa y más altura de miras; al que le hacen falta más absolutos aunque sean ingenuos, más héroes aunque sean falsos, más Apocalipsis aunque sean improbables. Watchmen fue un desafío y nadie duda ya de su éxito; pero algunas de las claves de ese desafío son recetas perfectamente viables hoy para un novelista (por ejemplo, español) que aspire a ofrecer algo más que una novelita previsible sobre la Guerra Civil o sobre espadachines del Siglo de Oro. ¿Con qué ingredientes? Algunos como éstos: la renuncia a la autoindulgencia a la hora de contar historias, la atención deliberada a la jerarquía objetiva de los problemas humanos, la aspiración a la dilatación del significado, $y$, en última instancia, la regeneración de la utopía creativa.

\section{Bibliografía}

Bajtin, Mijail. (1989). Teoría y estética de la novela. Trad. H.S. Kriúkova y VCazcarra. Madrid: Taurus.

Gracia, Jordi y Domingo Ródenas. (2011). Historia de la literatura española. 7. Derrota y restitución de la modernidad. Barcelona: Crítica.

Lukács, Georgy. (1971). Teoría de la novela. Barcelona: Edhasa.

Marín, Rafael. (2009). W de Watchmen. Palma de Mallorca: Dolmen. 